\title{
Pharmacy students' experience of a novel government-funded experiential learning initiative: A mixed-method study (ACTp Study)
}

\author{
Sabrina Anne Jacob ${ }^{1}(\mathbb{D})$, Tesnime Jebara ${ }^{2}(\mathbb{D})$, Margaret Watson ${ }^{3}(\mathbb{D})$, Scott Cunningham², Ailsa Power ${ }^{4}$, \\ Anne C Boyter ${ }^{1}$ (D) \\ ${ }^{1}$ Strathclyde Institute of Pharmacy and Biomedical Sciences, University of Strathclyde, Glasgow, United Kingdom \\ ${ }^{2}$ School of Pharmacy \& Life Sciences, Robert Gordon University, Aberdeen, United Kingdom \\ ${ }^{3}$ Watson Research and Training Limited, Aberdeen, United Kingdom \\ ${ }^{4} \mathrm{NHS}$ Education for Scotland, Glasgow, United Kingdom
}

\author{
Keywords \\ Experiential learning \\ MPharm \\ Out-of-hours \\ Pharmacy education \\ Primary care \\ Remote and rural

\section{Correspondence} \\ Anne C Boyter \\ Strathclyde Institute of Pharmacy \\ and Biomedical Sciences \\ University of Strathclyde \\ 161 Cathedral St \\ Glasgow G4 ORE \\ United Kingdom \\ anne.boyter@strath.ac.uk
}

\begin{abstract}
Background: In 2018, the Scottish Government made the Pharmacy Additional Cost of Teaching (ACTp) funding available to support the development of Experiential Learning (EL) in undergraduate pharmacy education. To inform the further expansion of EL in the pharmacy degree evaluation of new EL sites was required. Aim and method: A mixed-methods study was undertaken to determine students' perceptions of four new areas included in an EL pilot: primary care, out-of-hours, specialist sites, and remote and rural. Results: There were 43 survey respondents (response rate $72 \%$ ). Majority agreed the pilot had developed their clinical $(n=28,74 \%)$ and communication skills $(n=31,82 \%)$, and prepared them for future practice ( $n=30,79 \%$ ). One third felt the EL did not permit them to interact with patients. Focus group and interview participants were positive about their experience and the opportunity to experience new pharmacy roles in non-traditional settings. Many highlighted the lack of hands-on experience and facilitator feedback. Facilitator training and quality assurance of sites are warranted. Conclusions: Future work should focus on assessment of and feedback for students, and interprofessional opportunities within EL.
\end{abstract}

\section{Introduction}

In 2017, the Scottish Government launched Achieving Excellence in Pharmaceutical Care - A Strategy for Scotland, with a focus on training future pharmacists on how to work with other healthcare professionals within multidisciplinary teams (Scottish Government, 2017). This aligns with the Standards for the Initial Education and Training of Pharmacists from the General Pharmaceutical Council, the pharmacy regulator, which stipulates that all Master of Pharmacy (MPharm) degrees must include working with healthcare professionals and patients through practical experience (General Pharmaceutical Council, 2011). This is achieved through experiential learning (EL), where students gain skills by interacting with their practice environment and then reflecting on these experiences (Kolb \& Kolb, 2005; Egan \& Jaye, 2009).

Health services are facing increasing pressure and burden due to increased demand and reduced funding (Robertson et al., 2017). In Scotland, the number of people aged 60 years and above is predicted to rise by $50 \%$ over the next 10 to 15 years (Scottish Government, 2010; Burgess, 2019). The associated rise in chronic conditions and polypharmacy will lead to greater demand for all primary care services (Burgess, 2019). As such, governments and stakeholders have recommended 
that pharmacists should be fully utilised to increase capacity and help to meet this increased demand in these areas (General Pharmaceutical Council, 2015). The Scottish Government strategy for pharmaceutical care outlined the plan of "Integrating pharmacists with advanced clinical skills...in general practices to improve pharmaceutical care and contribute to the multidisciplinary team" (Scottish Government, 2017). The education and training of future pharmacists then need to reflect the anticipated need of providing extended pharmaceutical care services in novel settings and sectors (General Pharmaceutical Council, 2015).

Approximately $20 \%$ of the 5.454 million people in Scotland live in rural areas, and $25 \%$ of those living in rural areas are aged 65 years and above - higher than other areas in Scotland (Scottish Government, 2018). Individuals in remote and rural areas (defined as areas with a population of fewer than 3000 people, which are more than a 30 minute drive time from a settlement with a population of 10000 or more) (Scottish Government, 2016) have different health needs compared to urban-dwellers (Remote and Rural Steering Group, 2007), and often have to travel long distances to access health services, including pharmaceutical care (NHS Highland, 2015; Rushworth et al., 2015; Rushworth et al., 2018). In these areas, pharmacies struggle to recruit and retain pharmacists (Stewart et al., 2017), underlining the need for more pharmacists in this area and for EL to be expanded to create awareness and increase exposure among undergraduate student pharmacists to this area of practice.

Another potential emerging area for EL is NHS24 which is a special 'out of hours $(\mathrm{OOH})$ Health Board that was established to manage health problems in the community setting and reduce the burden on other existing National Health Service (NHS) systems during out of hours periods (Elliott et al., 2015). Since its inception in 2000, there has been an increase in demand for $\mathrm{OOH}$ services, with 1.6 million calls received in 2017/2018, an increase of approximately 20\% from 2014/2015 (Scottish Government, 2015; NHS24, 2018). A national review of $\mathrm{OOH}$ services highlighted the fragility and lack of sustainability of these services with a call for more multidisciplinary $\mathrm{OOH}$ health professionals, including pharmacists, to be urgently trained (Scottish Government, 2015).

In Scotland, the MPharm, an integrated masters level degree, is delivered by two universities, Robert Gordon University (RGU) and the University of Strathclyde (UoS). Experiential learning in these Schools of Pharmacy has traditionally been undertaken in hospital and community pharmacy, similar to other schools in the United Kingdom (UK) (Jacob \& Boyter, 2020b). EL sites were concentrated in the cities and areas of high population density, normally within one hour of travel from the University School of Pharmacy. In addition, limited financial support was available for students' travel and accommodation, both of which are arranged by students on their own. In 2018, the Scottish Government made the 'Pharmacy Additional Cost of Teaching' (ACTp) funding available to support the development of EL in both Schools of Pharmacy in Scotland (Wright, 2019) by supporting student travel and accommodation expenses and remuneration for the EL facilitators. This resulted in the opportunity to expand the areas in which EL could be delivered. Prior to that, the EL in Scotland received no funding, and the facilitators in these sites received no payment for hosting the students. In the UK, facilitators are registered, practising pharmacists who supervise pharmacy students during EL.

To the authors' knowledge, this is the first example of government funding of EL for student pharmacists in any country. In the first year of the ACTp funding (2018/19 academic year), four new areas were identified for inclusion in an EL pilot: primary care, remote and rural locations, specialist sites, and $\mathrm{OOH}$ /unscheduled care. In Scotland, primary care pharmacists work in general practices. The overall aim of this study was to explore students' experience of the novel ACTp-funded EL pilot and make recommendations for the next phase of expansion of EL.

\section{Methods \\ Study design}

A mixed-methods concurrent triangulation design was adopted, which comprised a cross-sectional survey, and semi-structured interviews, and focus group discussions (FGDs) involving undergraduate MPharm students who participated in the ACTp EL pilot. There was a total of 29 students from RGU and 31 students from UoS who volunteered to participate in the pilot. Ethical approval for this research project was granted by the Ethics Committees from both universities. Staff who were not involved in students' learning and teaching or planning and implementation of the pilots recruited students and conducted the qualitative research to prevent coercion. The survey was also anonymous, and no identifying details of respondents were collected.

\section{Data and participants}

Pilot sites were recruited through an email from NES. Many were hosting students for the first time. A total of 41 placement sites which were spread across most Scottish Health Boards participated: 18 primary care 
practices, ten specialist sites (e.g. mental health, prison service), eight remote and rural sites, four $\mathrm{OOH} /$ unscheduled care sites, and one 'combined package' (specialist, remote and rural, and primary care). All facilitators were invited to a Preparation for Facilitating Experiential Learning training event before the EL period. There was no mandatory quality assessment of the sites.

An invitation email was sent to penultimate and final year students in RGU and final year students in UoS asking for volunteers. The duration of the pilot EL was one week. This is similar to the duration of traditional EL. Prior to the pilot, students attended a preparatory briefing on expectations and professionalism and were given a handbook, which outlined their learning outcomes and responsibilities. A debriefing session was held after the pilot, where students were also able to share their experiences in the pilot sites with other students.

\section{Cross-sectional survey}

The survey was hosted on online platforms - Qualtrics and Online Surveys. An invitation email, along with the Participant Information Sheet, was sent by researchers to all 60 students who participated in the pilot, with an anonymous link to the survey. No financial incentives were offered, and a reminder email was sent one week after the initial email and one day before the closing date.

The survey comprised five open-ended and five closed-ended questions, the latter utilising five-point Likert-type scales ranging from strongly disagree to strongly agree. The questions explored student opinion of facilitators, EL sites, the organisation of the pilot, and feedback regarding their overall experience. Demographic details, including age and year of study, were collected. Respondents could omit responses to open-ended questions. The survey was adapted from a previously validated survey, which had been pilot tested (Jacob \& Boyter, 2020c). The survey took approximately five to ten minutes to complete.

\section{Interviews and focus groups}

A series of semi-structured interviews and FGDs adopting a descriptive qualitative research design were undertaken. Due to time constraints, a mixture of FGDs and interviews were undertaken, but using the same interview guide. An invitation was placed at the end of the cross-sectional survey asking potential volunteers to contact the researchers. Once student volunteers had been contacted, the authors purposively recruited participants, via email, from the remaining sites to ensure a maximum variation sample of sites and characteristics of different pilot sites. The interview guide was designed based on the study aims and validated for face and content validity by experts in qualitative design and health education. The guide was emailed to experts for comments, which were then collated and discussed with the research team. Modifications to the guide were then made if deemed necessary. The interviews and FGDs explored the activities undertaken during the placements, students' interactions with facilitators, and their perception of the ACTp EL pilot and its organisation.

Interviews and FGDs were conducted face-to-face at the respective universities by two researchers, $\mathrm{TJ}$ and SAJ. All sessions were audio-recorded, and field notes were taken to capture key points. Before the start of each session, the study aims were explained to participants, and those who consented were asked to sign consent forms. Participants were requested to provide some demographic details and were entered into a prize draw for a gift voucher.

\section{Data analysis}

Survey data were analysed using SPSS 24.0 (SPSS Inc, Chicago, IL, USA) and Microsoft Excel. Descriptive analysis was undertaken where continuous variables were expressed by means and standard deviations, whereas categorical data were presented using frequencies and percentages. The five-point Likert scale responses were collapsed to a three-point scale (agree, neutral, disagree). Thematic analysis was performed on the open-ended comments and combined with the qualitative findings. All interview and FGD recordings were transcribed verbatim by independent transcribers and anonymised before analysis. Transcripts were checked for accuracy. One FGD was independently coded by three researchers (MW, TJ, SAJ) to develop a coding framework and assess consistency. The remaining transcripts were coded by two researchers (TJ, SAJ), with new codes added to the framework as and when they occurred. Discrepancies were discussed with a third researcher (MW) and/or resolved by consensus. Thematic analysis was undertaken by two researchers (TJ, SAJ) based on the study aim. Data collection continued until theoretical saturation was achieved. Quotes are identified by the university, interview type and number, and placement site.

The methods and findings of the qualitative section of this study are reported according to the Consolidated Criteria for Reporting Qualitative Studies (COREQ) (Tong, Sainsbury, \& Craig, 2007) (Appendix 1). 


\section{Results}

\section{Cross-sectional survey}

The online survey was completed by 20 and 23 students from RGU and UoS, respectively (Table I). This represents response rates of $70 \%$ and $74 \%$ and an overall response rate of $72 \%$. Four respondents from UoS provided only demographic details and were excluded from the analysis.

Table I: Demographics of study participants

\begin{tabular}{|c|c|c|}
\hline \multirow[b]{2}{*}{ Characteristicst } & \multicolumn{2}{|c|}{$n(\%)$} \\
\hline & Survey respondents $(n=39)$ & $\begin{array}{l}\text { Interviewer and focus group } \\
\text { participants }(n=27)\end{array}$ \\
\hline Age, mean (SD) & $22.2(3.14)$ & $21.5(1.76)$ \\
\hline Females & $27(69.2)$ & $19(70.4 \%)$ \\
\hline \multicolumn{3}{|l|}{ University stage } \\
\hline Penultimate year & 15 (38.5) & $11(40.7)$ \\
\hline Final year & $24(61.5)$ & $16(59.3)$ \\
\hline \multicolumn{3}{|l|}{ ACTp EL pilot placement } \\
\hline Specialist & 6 15.4) & $5(18.5)$ \\
\hline Combined & $1(2.56)$ & $1(3.70)$ \\
\hline Primary care & $14(35.9)$ & $7(25.9)$ \\
\hline $\mathrm{OOH} /$ unscheduled care & $11(28.2)$ & $10(37.0)$ \\
\hline Remote and rural & 7 (17.9) & $4(14.8)$ \\
\hline \multicolumn{3}{|l|}{ Past or current work experience } \\
\hline Community pharmacy & $38(97.4)$ & $22(81.5)$ \\
\hline Hospital pharmacy & $28(71.8)$ & $13(48.1)$ \\
\hline GP & $8(20.5)$ & $4(14.8)$ \\
\hline NHS24 & $3(7.7)$ & $0(0)$ \\
\hline Remote and rural & $1(2.6)$ & $0(0)$ \\
\hline Other: Non NHS-laboratory based & $1(2.6)$ & $0(0)$ \\
\hline None & $1(2.6)$ & $0(0)$ \\
\hline
\end{tabular}

TSD=standard deviation; $\mathrm{ACT}=$ Additional Cost of Teaching; GP=general practice; NHS=National Health Service; OOH=Out-of-hours

Most respondents agreed that the ACTp EL pilot had developed their clinical $(n=28,74 \%)$ and communication skills $(n=31,82 \%)$ and had prepared them for their future practice $(n=30,79 \%)$. The majority were satisfied with their facilitators $(n=37$, $95 \%)$ and felt they were prepared for students $(n=33$, $85 \%$ ). Less than $50 \%$ agreed that facilitators had provided feedback after the EL $(n=19,49 \%)$, while $56 \%$ $(n=22)$ agreed that feedback was provided during EL. Most $(n=32,82 \%)$ agreed that they were able to interact with other healthcare professionals; however one third felt the pilot did not enable them to interact with patients. Thirty-four (87\%) respondents agreed they had a good experience overall. Less than $50 \%$ felt the pilot was well organised and that the information received before the pilot was useful (Table II).

\section{Interviews and focus groups}

In total, 27 students participated in the interviews and FGDs (Table I): three FGDs consisting of seven, eight, and four participants; and eight individual interviews. Individual interviews lasted an average of 22 minutes, while the FGDs took approximately an hour. Data saturation was achieved with no new themes emerging in the later interviews and FGDs. When analysed, there were no differences in responses based on EL site, except where mentioned below. The integrated results of the interviews, FGDs, and openended survey comments are presented using the themes: (1) perceived experience of the ACTp EL pilot, (2) challenges related to the ACTp EL pilot, and (3) suggestions for the improvement of future EL delivery (Figure 1 and Table III). 
Table II: Students' perspective of the ACTp EL pilot $(n=39)$

\begin{tabular}{|c|c|c|c|}
\hline Statementst & $\begin{array}{l}\text { Disagree } \\
\mathrm{n}(\%)\end{array}$ & $\begin{array}{c}\text { Neither agree } \\
\text { nor disagree } \\
\text { n (\%) }\end{array}$ & $\begin{array}{l}\text { Agree } \\
\text { n (\%) }\end{array}$ \\
\hline \multicolumn{4}{|l|}{ Facilitators } \\
\hline A member of staff orientated me to the site at the start of my EL pilot placement & $5(12.8)$ & $3(7.69)$ & $31(79.5)$ \\
\hline The facilitator(s) asked me what I wanted to achieve during my EL pilot placement & $1(2.56)$ & $1(2.56)$ & $37(94.9)$ \\
\hline The facilitator(s) were aware of the learning objectives for my EL pilot placement & $6(15.4)$ & $3(7.69)$ & $30(76.9)$ \\
\hline The facilitator(s) were prepared for my arrival & $3(7.69)$ & $3(7.69)$ & $33(84.6)$ \\
\hline The facilitator(s) provided feedback during my EL pilot placement & $8(20.5)$ & $9(23.1)$ & $22(56.4)$ \\
\hline The facilitator(s) provided feedback after my EL pilot placement & $11(28.2)$ & $9(23.1)$ & $19(48.7)$ \\
\hline $\begin{array}{l}\text { Workload allocation during my EL pilot placement was carefully planned by the } \\
\text { facilitator(s) }\end{array}$ & $4(10.3)$ & $5(12.8)$ & $30(76.9)$ \\
\hline The facilitator(s) were able to spend time with me & $0(0)$ & $2(5.13)$ & $37(94.9)$ \\
\hline Overall, I was satisfied with my facilitator(s) & $2(5.13)$ & $0(0)$ & $37(94.9)$ \\
\hline \multicolumn{4}{|l|}{ Placement sites } \\
\hline The EL pilot placement site enabled me to interact with other healthcare professionals & $5(12.8)$ & $2(5.13)$ & $32(82.1)$ \\
\hline The EL pilot placement site enabled me to interact with patients & $13(33.3)$ & $5(12.8)$ & $21(53.8)$ \\
\hline The staff at my EL pilot placement site were supportive of me & $1(2.56)$ & $2(5.13)$ & $36(92.3)$ \\
\hline It was easy to travel to my EL pilot placement site(s) & $11(28.2)$ & $5(12.8)$ & $23(59.0)$ \\
\hline The EL pilot placement site had enough space to accommodate me as a student & $2(5.13)$ & $1(2.56)$ & $36(92.3)$ \\
\hline Overall, I had a good experience in the EL pilot placement site & $3(7.69)$ & $2(5.13)$ & $34(87.2)$ \\
\hline \multicolumn{4}{|l|}{ Organisation } \\
\hline $\begin{array}{l}\text { The information that I was given by my university prior to my EL pilot placement was } \\
\text { useful }\end{array}$ & $12(30.8)$ & $9(23.1)$ & $18(46.2)$ \\
\hline The EL pilot placements were well organised by my university & $13(33.3)$ & $9(23.1)$ & $17(43.6)$ \\
\hline $\begin{array}{l}\text { I received sufficient support from the university on matters related to my EL pilot } \\
\text { placement }\end{array}$ & $8(20.5)$ & $6(15.4)$ & $25(69.4)$ \\
\hline The university staff involved in the EL pilot placements were very supportive & $3(7.69)$ & $11(28.2)$ & $25(69.4)$ \\
\hline $\begin{array}{l}\text { I had a schedule of planned activities provided to me at the start of my EL pilot } \\
\text { placement }\end{array}$ & $5(12.8)$ & $4(10.3)$ & 30 (76.9) \\
\hline My planned activities met my learning needs & $8(20.5)$ & $6(15.4)$ & $25(69.4)$ \\
\hline
\end{tabular}

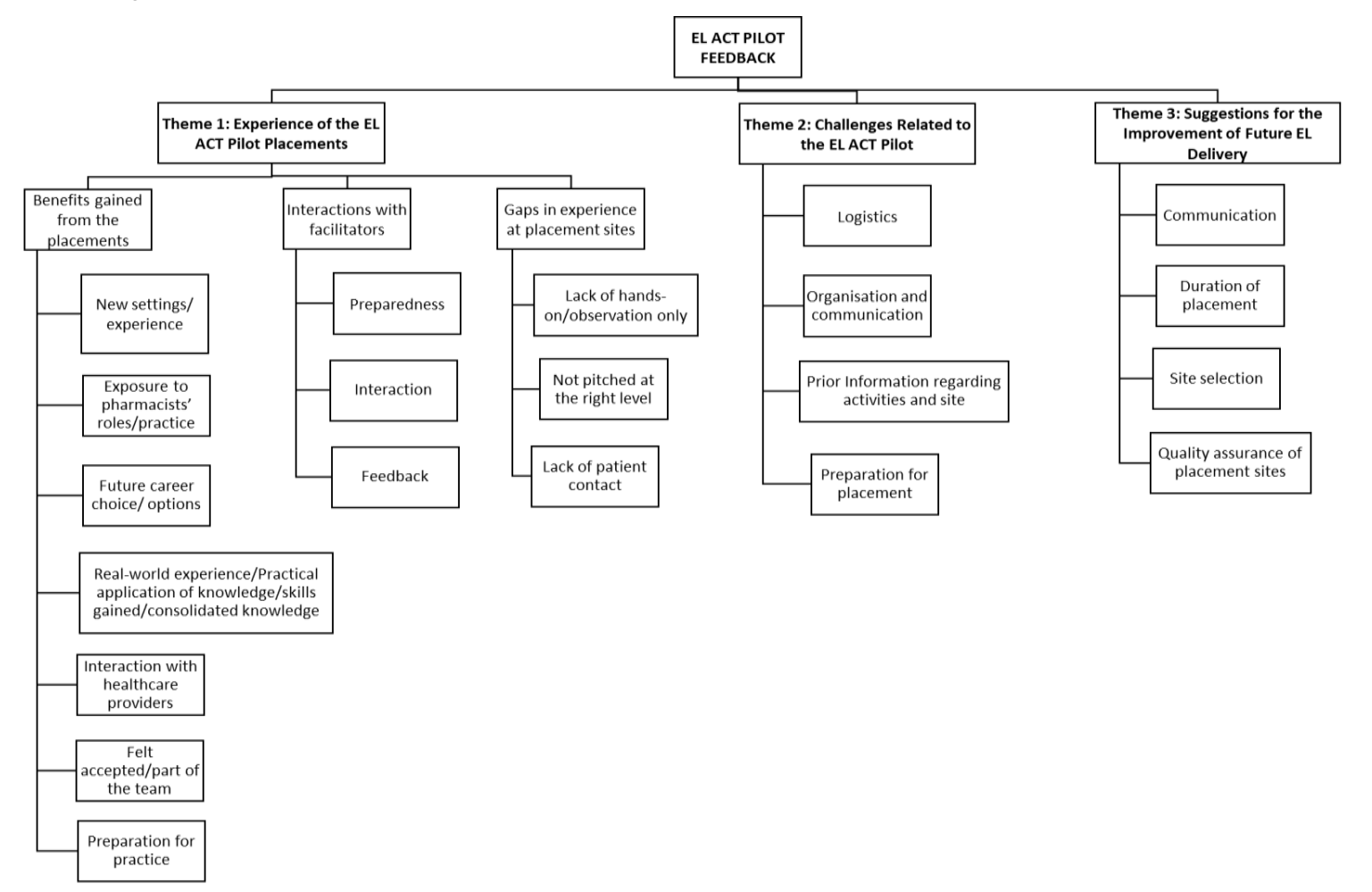

Figure 1: Students' perspectives of the EL pilot placements 
Table III: Themes, sub-themes and illustrative quotes from interviews and focus group discussions

\begin{tabular}{|c|c|c|}
\hline Theme & Sub-sub theme & Illustrative quotes ${ }^{a, b}$ \\
\hline \multicolumn{3}{|c|}{ Theme 1: Perceived experience of the ACTp EL pilot } \\
\hline \multirow{4}{*}{$\begin{array}{l}\text { Subtheme 1: } \\
\text { Benefits } \\
\text { gained from } \\
\text { the } \\
\text { placements }\end{array}$} & $\begin{array}{l}1.1 \text { New settings/ } \\
\text { experience }\end{array}$ & $\begin{array}{l}\text { "...it was far better than being in community pharmacy. I've worked in community pharmacy } \\
\text { and I feel I've covered most of that but this was just a totally different thing and it showed us } \\
\text { how a specialised health board worked..." (RGU-FGD\#1-4, OOH/unscheduled care) }\end{array}$ \\
\hline & $\begin{array}{l}1.2 \text { Exposure to } \\
\text { pharmacists' roles/practice }\end{array}$ & $\begin{array}{l}\text { "I think it was good to see the variable roles that pharmacists have }[. . .] \text { even in GP practices } \\
{[\ldots . .] \text { so it was good to see how pharmacists can contribute to the multidisciplinary team }} \\
\text { especially within secondary care..." (UoS-FGD\#1-8, Primary care) }\end{array}$ \\
\hline & $\begin{array}{l}\text { 1.3 Future career } \\
\text { choice/options }\end{array}$ & $\begin{array}{l}\text { "...although I came into it thinking that I would only want to stay in hospital, [...], I have actually } \\
\text { really enjoyed my time in primary care, it's something I can see myself doing, so it's opened up } \\
\text { potential career paths for me, which is great" (UoS-FGD\#2-1, Primary care) }\end{array}$ \\
\hline & $\begin{array}{l}\text { 1.4 Real-world } \\
\text { experience/practical } \\
\text { application of } \\
\text { knowledge/skills } \\
\text { gained/consolidated } \\
\text { knowledge }\end{array}$ & $\begin{array}{l}\text { "...the pharmacist would actively ask what I thought about the different cases and what I } \\
\text { thought would need to be reviewed before they were discharged and also doing a lot of like } \\
\text { medicines reconciliations with the patients, being able to see how they were actually carried } \\
\text { out in real life, and they weren't all as I guess textbook as we'd see in the university here." } \\
\text { (RGU-I-3, Remote and rural) }\end{array}$ \\
\hline
\end{tabular}

1.5 Interaction with healthcare providers

1.6 Felt accepted/part of the team

1.7 Preparation for practice

Subtheme 2: 2.1 Preparedness Interactions with facilitators

2.2 Interaction

2.3 Feedback

Subtheme 3: 3.1 Lack of handsGaps in on/observation only experience at 3.2 Lack of patient contact placement sites

"...it was good to see all the interprofessional people coming together, a different profession, social work, the nurses, mental health nurses, psychiatrists, so I'd never had any experience working with, say, psychiatrists before so it was nice to see, that kind of side of it as well..." (RGU-I-1, Remote and rural)

"I think the most important change that made it worthwhile was the fact that I was part of the team, rather than just a burden on the team, to be honest, and that's the first time I've experienced that in a placement." (UoS-FGD\#2-1, Primary care)

"I feel like I'm more equipped to, work as a locum [...] and not be too comfortable in where I sort of work, so I feel like I'm more equipped to sort of look and deal with new experiences and deal with them in a good way, rather than sort of panic..." (UoS-FGD\#2-2, OOH/unscheduled care)

"Communication skills with patients, getting to see professionals do it and then getting to do it myself. I think after doing that and seeing how l've done, got the feedback from the pharmacist, I felt quite confident there. I can definitely see myself actually doing this now." (RGU-I-6, Primary care)

“...sometimes the pharmacist, in the afternoon would be like, I'm not going to be in, because I'm busy at a different surgery, or something like that, the roles weren't fully developed yet, so sometimes it was a wee bit of moving about and trying to fix the timetable on the day, rather than staying on the fixed timetable." (UoS-FGD\#1-8, Primary care)

"They were really friendly and really keen to get me involved in stuff and, they trusted me a lot to kind of lead the interviews, and they had a lot of time for me, to like answer my questions, and they were really good at kind of contacting other staff members to get me to see a variety of things." (RGU-I-6, Primary care)

"I would've liked more feedback... But I think that was again because there weren't any specific objectives so how can you know if you're doing good or bad, if you don't actually know what you're there to be completing." (RGU-FGD\#1-5, Remote and rural)

"...you got to see the processes that you should be using, but at the same time you weren't really able to use them yourself, because you were just observing" (UoS-FGD\#1-8, Primary care)

"I do wish that I could've seen a lot more patients but again, I think in primary care, there's just so much paperwork to do as well it's hard, they didn't see a lot of patients themselves..." (RGUFGD\#1-1, Primary care)

3.3 Not pitched at the right "I don't think they knew what we knew as students, as well, at the same time, they kind of level underestimated us in a way, because I think the old courses were different to the new course, and we were coming out with a whole different set of skills or subset of skills, which they weren't aware of..." (UoS-FGD\#1-8, Primary care)

Theme 2: Challenges related to the ACTp EL pilot

1. Logistics

2. Organisation and communication “...biggest challenge [...] was probably getting to all the different placements and knowing where to go, as it was quite tight on time for that, I was having to get from lunchtime then to another area to a different practice." (RGU-I-7, Primary care)

“...I was told on the day, 'oh you're going to $S^{*}$ tomorrow', which I didn't actually realise it's an hour and 20 minutes on the bus, so, it was there and then back again at night, it was something that I hadn't planned for, and I didn't know where I was going, and I had to navigate through $S^{*}$, and walk about a mile and bit through the town to try and find the hospital, so logistically it was a bit of a mess." (UoS-FGD\#2-1, Primary care) 


\begin{tabular}{|c|c|c|}
\hline Theme & Sub-sub theme & Illustrative quotes ${ }^{a, b}$ \\
\hline & $\begin{array}{l}\text { 3. Prior information } \\
\text { regarding activities and site }\end{array}$ & $\begin{array}{l}\text { "I didn't know at all what I was going to be doing during the week. It wasn't until I got there on } \\
\text { the first day that I got my timetable for the rest of the week. (RGU-I-7, Primary care) }\end{array}$ \\
\hline & & $\begin{array}{l}\text { "Mine was just so different, it's like nothing that I've ever experienced, but I think you just can't } \\
\text { prepare for it, [...] I just came across stuff that I would never have thought that I would even be } \\
\text { doing in the first place..." (UoS-FGD\#2-4, Specialist, Remote \& Rural, and GP combined package) }\end{array}$ \\
\hline \multicolumn{3}{|c|}{ Theme 3: Suggestions for the improvement of future EL delivery } \\
\hline & 1. Communication & $\begin{array}{l}\text { "...a bit more information about each of the different locations, and each of the different areas } \\
\text { that you could potentially go as part of the programme would have been a lot better, because } \\
\text { then you can at least make an informed decision." (UoS-FGD\#1-5, Primary care) }\end{array}$ \\
\hline & \multirow[t]{2}{*}{ 2. Duration of placement } & $\begin{array}{l}\text { "I'd say a week was probably a good amount of time to get to experience enough but also not } \\
\text { be there too long that you then felt you didn't have a whole lot to do." (RGU-I-7, Primary care) }\end{array}$ \\
\hline & & $\begin{array}{l}\text { "I feel like if you've worked in a community pharmacy then things can get really, really, really } \\
\text { repetitive in different community pharmacies so, I feel like one or two days you've seen the } \\
\text { difference between the pharmacy you would normally work in and then the pharmacy you've } \\
\text { been placed in." (RGU-FGD\#1-2, Remote and rural) }\end{array}$ \\
\hline & 3. Site selection & $\begin{array}{l}\text { "If the uni's actually like 'no you're going to go primary care' or 'you're going to go to hospital' } \\
\text { so it would really teach them more, seeing different pharmacists in different roles." (RGU-I-6, } \\
\text { Primary care) }\end{array}$ \\
\hline & $\begin{array}{l}\text { 4. Quality assurance of } \\
\text { placement sites }\end{array}$ & $\begin{array}{l}\text { "...there needs to be more kind of a spot check for the pharmacies themselves, [...] even just } \\
\text { walking into a pharmacy and seeing, not interacting, but just seeing how busy they are, they } \\
\text { know, actually that pharmacy is too busy for a student to get a good experience..." (UoS- } \\
\text { FGD\#1-1, Remote and rural) }\end{array}$ \\
\hline
\end{tabular}

${ }^{\mathrm{a}} \mathrm{OOH}=$ Out of Hours; FGD=Focus group discussion

bInterview and focus group participants are identified according to their university, interview type and number, and placement site.

\section{Theme 1: Perceived experience of the ACTP EL pilot}

Students expressed how the pilot enabled them to experience novel settings and exposure to pharmacists' roles of which they were previously unaware, with one admitting;

"...we didn't even realise that there was even pharmacists in NHS24 before we went." (RGUFGD\#1-4, OOH/unscheduled care).

This helped contradict some preconceived notions, such as the fact that pharmacists were rarely patientfacing or had limited interactions with other healthcare professionals. This exposure also influenced students' intentions regarding future career choices, with some reporting that they would consider pharmacy roles of which they had little awareness before the pilot.

Students felt the real-world experience gained from the pilot provided a better perspective of what they learned in university, noting it painted a more realistic picture of patient interactions. Additionally, some felt they were able to apply the knowledge they had gained in university. Students shared that they interacted with different healthcare professionals, which was not previously experienced in the traditional EL, and learned more about their roles and services, noting that this would help prepare them for future practice and enable them to communicate effectively as members of the healthcare team. Students felt accepted and part of their EL team and perceived their opinions to be valued, and that staff were interested in teaching them. Unlike previous EL, the students did not feel as if they were inconveniencing their facilitators or teams, stating:

"...I was part of the team, rather than just a burden on the team..." (UoS-FGD\#2-1, Primary care)

Most students reported feeling satisfied with their facilitators and felt they were able to spend time with them, noting:

"...how structured it was...they were so prepared." (RGU-FGD\#1-3, OOH/unscheduled care).

Some, though, perceived their EL activities to be more opportunistic than planned. Many lamented the lack of feedback received from facilitators, although some reflected that this was probably because of the limited activity that students were allowed to undertake. A few students highlighted that anonymous feedback could be the way forward to ensure honesty in evaluating student performance. According to students, facilitators wanted to receive feedback from them on their EL experience and how they could improve, especially those pharmacists facilitating EL for the first time.

One of the main shortcomings highlighted by students was the lack of interaction with patients, as activities were limited to observation and students were only permitted to shadow pharmacists. This limitation was of particular relevance at the $\mathrm{OOH} /$ unscheduled care 
sites. Although students were able to listen to live calls, they were not permitted to manage these calls or to interact with the service users during the pilot EL. Students across sites also expressed frustration that the experience was not pitched at the right level, noting that facilitators often lacked an understanding of students' capabilities and level of knowledge.

\section{Theme 2: Challenges related to the ACTP EL pilot}

The main challenges highlighted by students were related to travel and overnight accommodation. This was attributed to a lack of timely information from their universities, which impeded effective planning. Some students felt they could not adequately prepare for their EL, attributing this to their lack of familiarity with the type of site, the limited information provided by the university, as well as their university coursework demands. As noted by one student:

"I didn't really prepare for it because I think if it had been the community pharmacy placement I would've prepared by looking over the CMS (Chronic Medication Service) stuff but I wasn't entirely sure what I was going to learn in the week." (RGU-I-6, Primary care)

Theme 3: Suggestions for the improvement of future EL delivery

Students emphasised the need for more information before their EL, especially the activities to be undertaken, noting that this would also assist them in choosing the type of EL site. Students also suggested that facilitators needed to be aware of students' competencies and knowledge to enable the former to undertake a wider range of activities than those permitted during the pilot:

"It would be nice if the pharmacies or the hospitals [...] sort of knew your limitations, and what your competencies, like what your knowledge is [...] I feel like that would be much more beneficial because that would prepare us for pre-reg year, where we're actually going to get let loose in the wild, and actually have to do these things..." (UoS-FGD\#1-6, OOH/unscheduled care)

Students were ambivalent about the duration of EL, and this was influenced by their experience at their EL site as well as previous part-time community pharmacy experience. Students who were placed at $\mathrm{OOH} / \mathrm{unscheduled}$ care service and primary care suggested that one week was sufficient because beyond that, they would not have anything to do. Students suggested that they should be able to choose their own EL site to reflect their own interests, commenting:
"I think it would be good for people to have a say because if it's something you're interested in, you're going to get more out of the week." (RGU-I-7, Primary care)

Others, however, acknowledged that if their university assigned the allocation, it would encourage them to try new areas of pharmacy practice. Some students suggested that the universities should undertake quality assurance measures to ensure the appropriateness and ability of EL sites to host students.

\section{Discussion}

Findings from this study suggest that students had a mostly positive experience and considered that their EL helped them prepare for practice and developed their skills. They valued the real-world exposure afforded by EL, including their interactions with healthcare professionals, team working, as well as improving their awareness of the roles of pharmacists in nontraditional settings, the latter influencing potential job options.

\section{Value of interactions with other healthcare professionals}

According to the Social Identity Theory, students will form positive opinions about their own profession but negative ones of those from other professions, creating an 'us-them' mentality due to the lack of interprofessional interactions (Tajfel \& Turner, 1986). Healthcare professionals have also been 'socialised to adopt the healthcare worldview characteristic of their own profession' (Clark, 2006). This could potentially lead to a clash of egos in the workplace, with patient care being affected as healthcare professionals struggle to see problems and potential solutions from the eyes of other healthcare professionals (Clark, 2006; Orchard, 2010; Williams \& Webb, 2015). Healthcare students have previously noted that receiving training only in uni-professional groups meant they lacked awareness of the competencies of other healthcare professionals (Reime et al., 2017). This ACTp EL pilot, however, allowed for more exposure and interactions with healthcare professionals in a variety of settings. This could assist in consolidating this awareness, and in turn, influence future career paths (Abdu-Aguye et al., 2019; Malson, 2016), as evidenced by this study. This factor could also be beneficial for addressing workforce capacity in sectors and roles that have not traditionally involved student EL, for example, in remote and rural communities. 


\section{Students as active participants in their learning}

There was considerable variation in the extent to which the students had hands-on experience. Students with little experience in novel settings have found the volume and complexity of information they are exposed to challenging (McCartney \& Boschmans, 2018). As noted by Eberlein and authors in 2008, the human mind has limitations on the amount of information it can process, and as cognitive load increases, students will need to interact more actively with it instead of being passive observers to be able to comprehend it. It has been found that compared to those who were just observing, students who were more hands-on developed better clinical decisionmaking, communication, and team-working skills (Reime et al., 2017). 'Learning by doing' allows better integration of theory and practice, and facilitates deeper learning to occur (Reime et al., 2017).

In keeping with the tenets of social constructivism subscribed to by EL theories, facilitators need to be encouraged to adopt social learning methods where students are active participants and learn through cooperative interactions with others, such as working in multidisciplinary groups, which will also assist in building interprofessional relationships (Eberlein et al., 2008; Kritikos et al., 2011; Mohaupt et al., 2012; Mohamed Ibrahim, 2018). An ambition of the ACTp work is to allow all students 'to do' rather than 'observe', and this will be worked on in future academic years through facilitator training, which helps them understand students' knowledge as they progress through the MPharm. Being more hands-on will also allow students to fully immerse themselves in the experience, which is necessary to facilitate reflection, a key process in the EL cycle, as illustrated by Kolb (Kolb \& Kolb, 2005).

\section{Importance of feedback}

Feedback is important in the EL cycle as it forms the base for students' reflections and is important for developing professionalism (Hammer, 2006; Quinton \& Smallbone, 2010). Students in this study, however, highlighted the fact that minimal to no feedback was received from facilitators during the pilot, and this can be attributed to the fact that many facilitators were not yet trained in providing feedback (Mitra Assemi et al., 2011; Fejzic et al., 2013). In interviews and FGDs involving graduates of an undergraduate MPharm programme who were currently undertaking their preregistration training, participants highlighted that facilitator feedback during EL was important as it would prepare them for their pre-registration period, where feedback was at the very essence of pre-registration training. They also felt that a formalised feedback process would ensure facilitators were engaged with them (Jacob \& Boyter, 2020a). Going forward, all EL facilitators will have appropriate training by NES and the universities before accepting a student for EL, and this will ensure facilitators will be able to support and facilitate students' learning experience in an effective manner. Quality assurance of EL sites is also planned as ACTp-funded activities expand.

\section{Recommendations and further work}

We recommend that the facilitator training is expanded to all EL facilitators (NHS for Education Scotland, 2019). This, coupled with the introduction of quality assurance of the sites, should improve the student and facilitator experience (Mitra Assemi et al., 2017). Measures to ensure that students' travel and accommodation are managed through a university process should be implemented to ensure students are not arranging this themselves. This will remove barriers to $E L$ in remote and rural locations. Further work should focus on feedback on student performance in EL and how this can be linked to student assessment, and how interprofessional learning can be integrated better into EL.

\section{Strengths and limitations}

Among the strengths of the study are the fact that purposive sampling for the interviews and FGDs ensured representation from all types of sites. Good response rates $(70 \%)$ were achieved with the online survey, with similar rates achieved across both universities. The study was conducted shortly after EL, which minimised the risk of recall bias. With regard to limitations, students from each university used different EL handbooks, which outlined different learning outcomes, and this could have affected their experience and subsequent feedback. Due to time constraints, a pilot study was not undertaken of the survey. However, there was a minimal adaption from a previously validated and piloted survey; therefore we felt further piloting was not needed. Due to logistics, both interviews and FGDs were undertaken. However, as the same interview guide was used, we anticipate a minimal impact on students' responses. Those who volunteered to participate in the pilot as well as interviews and FGDs were likely to be more engaged with a lower propensity to demonstrate poor attitude. Readers should take this into consideration when reviewing the findings. 


\section{Conclusion}

This novel ACTp-funded EL pilot was generally wellreceived by the student participants. Our findings highlight the importance of interactions with other healthcare professionals as well as the value of sending students to these non-traditional placement sites. Students should be allowed to have more hands-on experience, and feedback should be prioritised, given the value of both to the EL process. The logistics of future EL require further refinement, including travel and accommodation. The expectations of both students and facilitators could be better managed with the provision of relevant and timely information.

\section{Source of funding}

This study was supported by an educational grant received from NHS Education for Scotland (NES).

\section{Acknowledgements}

We thank the students who participated in the evaluation project. We are grateful for the transcribing services provided by Accu-Scribe Transcribing and Data Entry Services and Redballoon PA.

\section{References}

Abdu-Aguye, S. N., Yusuf, H., Agbale, E. O., Auwal, F. I., \& Ma'aji, H. U. (2019). Connections between classroom theory \& real world practice: Exploring the perspectives of undergraduate students at a Nigerian faculty of pharmacy. Pharmacy Education, 19(1), 185-189

Assemi, M., Corelli, R. L., \& Ambrose, P. J. (2011). Development Needs of Volunteer Pharmacy Practice Preceptors. American Journal of Pharmaceutical Education, 75(1), Article 10. https://doi.org/10.5688/ajpe75110

Assemi, M., DiVall, M. V., Lee, K., Sy, E., \& O’Sullivan, T. (2017). Quality Assurance and Improvement Practices of Experiential Education Programs in Schools of Pharmacy. American Journal of Pharmaceutical Education, 83(3), Article 6582. https://doi.org/10.5688/ajpe6582

Burgess, L. (2019). Primary Care in Scotland. Retrieved from https://digitalpublications.parliament.scot/ResearchBriefing s/Report/2019/5/29/Primary-Care-in-Scotland. Accessed $29 / 6 / 2020$

Clark, P. G. (2006). What would a theory of interprofessional education look like? Some suggestions for developing a theoretical framework for teamwork training. Journal of Interprofessional Care, 20(6), 577-589. https://doi.org/10.1080/13561820600916717

Eberlein, T., Kampmeier, J., Minderhout, V., Moog, R. S., Platt, T., Varma-Nelson, P., \& White, H. B. (2008).
Pedagogies of engagement in science: A comparison of $\mathrm{PBL}$, POGIL, and PLTL*. Biochemistry and Molecular Biology Education, 36(4), 262-273. https://doi.org/10.1002/bmb.20204

Egan, T., \& Jaye, C. (2009). Communities of clinical practice: the social organization of clinical learning. Health, 13(1), 107-125. https://doi.org/10.1177/1363459308097363

Elliott, A. M., McAteer, A., Heaney, D., Ritchie, L. D., \& Hannaford, P. C. (2015). Examining the role of Scotland's telephone advice service (NHS 24) for managing health in the community: analysis of routinely collected NHS 24 data. BMJ Open, 5(8), e007293.

https://doi.org/10.1136/bmjopen-2014-007293

Fejzic, J., Henderson, A., Smith, N. A., \& Mey, A. (2013). Community pharmacy experiential placement: Comparison of preceptor and student perspectives in an Australian postgraduate pharmacy programme. Pharmacy Education, 13(1), 15-21

General Pharmaceutical Council. (2011). Future pharmacists: Standards for the initial education and training of pharmacists. Available at:

https://www.pharmacyregulation.org/sites/default/files/do cument/gphc_future_pharmacists_may_2011.pdf

General Pharmaceutical Council. (2015). Tomorrow's pharmacy team: Future standards for the initial education and training of pharmacists, pharmacy technicians and pharmacy support staff. Available at:

https://www.pharmacyregulation.org/sites/default/files/to morrows_pharmacy_team_june_2015.pdf

Hammer, D. (2006). Improving Student Professionalism During Experiential Learning. American Journal of Pharmaceutical Education, 70(3), 59. https://doi.org/10.5688/aj700359

Jacob, S. A., \& Boyter, A. (2020a). "It has very good intentions but it's not quite there yet": Graduates' feedback of experiential learning in an MPharm programme Part 2 (TELL Project). Studies in Educational Evaluation, 66, 100889. https://doi.org/10.1016/j.stueduc.2020.100889

Jacob, S. A., \& Boyter, A. (2020b). Nationwide survey of experiential learning in MPharm programmes in UK Universities. International Journal of Pharmacy Practice, 28(2), 121-129. https://doi.org/10.1111/ijpp.12521

Jacob, S. A., \& Boyter, A. (2020c). Survey of undergraduates' perceptions of experiential learning in the MPharm programme: The TELL Project. Pharmacy Practice, 18(2). https://doi.org/10.18549/PharmPract.2020.2.1856

Kolb, A. Y., \& Kolb, D. A. (2005). Learning Styles and Learning Spaces: Enhancing Experiential Learning in Higher Education. Academy of Management Learning \& Education, 4(2), 193-212. https://doi.org/10.5465/amle.2005.17268566

Kritikos, V. S., Woulfe, J., Sukkar, M. B., \& Saini, B. (2011). Intergroup peer assessment in problem-based learning tutorials for undergraduate pharmacy students. American Journal of Pharmaceutical Education, 75(4), 7373.https://doi.org/10.5688/ajpe75473

Malson, G. (2016). Placements for pharmacy students and trainees in GP practices and primary care. The Pharmaceutical Journal, August. https://doi.org/10.1211/PJ.2016.20201630 
McCartney, J., \& Boschmans, S.-A. (2018). South African pharmacy student perspectives of a hospital-based experiential learning programme. Pharmacy Education, 18(1), $29-40$

Mohamed Ibrahim, M. I. (2018). Chapter 3 - Philosophy, Theories, Models, and Strategies in Pharmacy Education: An Overview. In A. I. Fathelrahman, M. I. Mohamed Ibrahim, A. A. Alrasheedy, \& A. I. Wertheimer (Eds.), Pharmacy Education in the Twenty First Century and Beyond (pp. 2139). London, United Kingdom: Academic Press. https://doi.org/10.1016/B978-0-12-811909-9.00003-4

Mohaupt, J., van Soeren, M., Andrusyszyn, M.-A., MacMillan, K., Devlin-Cop, S., \& Reeves, S. (2012). Understanding interprofessional relationships by the use of contact theory. Journal of Interprofessional Care, 26(5), 370375. https://doi.org/10.3109/13561820.2012.673512

NHS24. (2018). Delivering a Healthier Scotland Together: Annual Report 2017/2018. Available at:

https://www.nhs24.scot/data/uploads/pdf/reports/annualreview/ph8177-annual-report-01_02_19.pdf

NHS for Education Scotland. (2019). Preparation for Facilitating Experiential Learning Training (PFEL). Available at: https://www.nes.scot.nhs.uk/education-andtraining/by-discipline/pharmacy/experiential-learning-forstudent-pharmacists-in-scotland/preparation-forfacilitating-experiential-learning-training-(pfel).aspx

NHS Highland. (2015). Pharmacy teams focus on innovation in remote and rural areas. Available at:

https://www.nhshighland.scot.nhs.uk/News/Pages/Pharma cyteamsfocusoninnnovationinremoteandruralareas.aspx

Orchard, C. A. (2010). Persistent isolationist or collaborator? The nurse's role in interprofessional collaborative practice. Journal of Nursing Management, 18(3), 248-257. https://doi.org/10.1111/j.1365-2834.2010.01072.x

Quinton, S., \& Smallbone, T. (2010). Feeding forward: using feedback to promote student reflection and learning - a teaching model. Innovations in Education and Teaching International, 47(1), 125-135. https://doi.org/10.1080/14703290903525911

Reime, M. H., Johnsgaard, T., Kvam, F. I., Aarflot, M., Engeberg, J. M., Breivik, M., \& Bratteb $\varnothing$, G. (2017). Learning by viewing versus learning by doing: A comparative study of observer and participant experiences during an interprofessional simulation training. Journal of Interprofessional Care, 31(1), 51-58. https://doi.org/10.1080/13561820.2016.1233390

Remote and Rural Steering Group. (2007). Delivering for Remote and Rural Healthcare: the Final Report of the Remote and Rural Workstream. Available at: https://www.ficm.ac.uk/sites/default/files/scotland_remote _and_rural.pdf

Robertson, R., Wenzel, L., Thompson, J., \& Charles, A. (2017). Understanding NHS financial pressures: How are they affecting patient care? Available at: https://www.kingsfund.org.uk/sites/default/files/field/field _publication_file/Understanding\%20NHS\%20financial\%20pr essures\%20-\%20full\%20report.pdf

Rushworth, G. F., Cunningham, S., Pfleger, S., Hall, J., \& Stewart, D. (2018). A cross-sectional survey of the access of older people in the Scottish Highlands to general medical practices, community pharmacies and prescription medicines. Research in Social and Administrative Pharmacy, 14(1), 76-85. https://doi.org/10.1016/j.sapharm.2017.01.002

Rushworth, G. F., Diack, L., MacRobbie, A., Munoz, S., Pfleger, S., \& Stewart, D. (2015). Access to medicines in remote and rural areas: a survey of residents in the Scottish Highlands \& Western Isles. Public Health, 129(3), 244-251. https://doi.org/10.1016/j.puhe.2015.01.005

Scottish Government. (2010). Demographic Change in Scotland. Available at:

https://www.gov.scot/binaries/content/documents/govscot /publications/research-and-analysis/2010/11/demographicchange-scotland/documents/0108163-pdf/0108163pdf/govscot\%3Adocument/0108163.pdf

Scottish Government. (2015). Pulling together: transforming urgent care for the people of Scotland. The Report of the Independent Review of Primary Care Out of Hours Services: Main Report. Available at:

https://www.gov.scot/binaries/content/documents/govscot/p ublications/progress-report/2015/11/main-report-nationalreview-primary-care-out-hours-services/documents/00489938pdf/00489938-pdf/govscot\%3Adocument/00489938.pdf

Scottish Government. (2016). Scottish Government Urban Rural Classification 2016. Available at: https://www.gov.scot/publications/scottish-governmenturban-rural-classification-2016/pages/2/

Scottish Government. (2017). Achieving Excellence in Pharmaceutical Care - A Strategy for Scotland. Available at: https://www.gov.scot/publications/achieving-excellencepharmaceutical-care-strategy-scotland/. Accessed 3/6/2020

Scottish Government. (2018). Rural Scotland Key Facts 2018. Available at:

https://www.gov.scot/binaries/content/documents/govscot/publi cations/statistics/2018/10/rural-scotland-key-facts2018/documents/rural-scotland-key-facts-2018-pdf/ruralscotland-key-facts-2018-pdf/govscot\%3Adocument/00541327.pdf

Stewart, D., Anthony, B., Morrison, C., MacRae, Y., Dixon, L., Friel, E., ... MacLure, K. (2017). Evaluating pharmacist input into the pharmaceutical care of patients in dispensing medical practices in remote and rural areas of Scotland. Family Practice, 34(4), 491-499. https://doi.org/10.1093/fampra/cmx014

Tajfel, H., \& Turner, J. (Eds.). (1986). The social identity theory of intergroup behaviour Chicago, IL: Nelson-Hall

Tong, A., Sainsbury, P., \& Craig, J. (2007). Consolidated criteria for reporting qualitative research (COREQ): a 32item checklist for interviews and focus groups. International Journal for Quality in Health Care, 19(6), 349-357. https://doi.org/10.1093/intqhc/mzm042

Williams, B., \& Webb, V. (2015). A national study of paramedic and nursing students' readiness for interprofessional learning (IPL): Results from nine universities. Nurse Education Today, 35(9), e31-e37. https://doi.org/10.1016/j.nedt.2015.05.007

Wright, S. (2019). Scottish government invests $f 2.85 \mathrm{~m}$ to expand experiential learning of student pharmacists to new settings. The Pharmaceutical Journal, March. https://doi.org/10.1211/PJ.2019.20206248 